\title{
Expression and significance of glucose-regulated protein 78 in human osteosarcoma
}

\author{
YONGKUI ZHANG ${ }^{1}$, NIANHU LI ${ }^{1}$, DONGLI WANG ${ }^{1}$, YIQIANG CHEN ${ }^{2}$ and GANG LI ${ }^{1}$ \\ ${ }^{1}$ Department of Orthopedics, Affiliated Hospital of Shandong University of Traditional Chinese Medicine, Jinan; \\ ${ }^{2}$ Department of Orthopedics, The First People's Hospital of Tai'an City, Tai'an, Shandong, P.R. China
}

Received June 30, 2014; Accepted February 20, 2015

DOI: 10.3892/ol.2015.3030

\begin{abstract}
The present study aimed to investigate the expression of glucose-regulated protein 78 (GRP78) in osteosarcoma cells, and analyze the differences in expression between tumor and normal tissues, pre- and post-chemotherapy patients and metastatic and non-metastatic tumors. According to these results, the associations between the expression of GRP78 and tumor growth, metastasis and chemotherapeutics could be determined. Between 2007 and 2012, 60 patients who had been diagnosed with osteosarcoma were selected for the present study. Of these patients, 20 presented with non-metastatic tumors and 40 with metastatic tumors, and 20 had been treated without chemotherapy and 40 with chemotherapy. In addition, 60 specimens obtained from adjacent normal tissues were collected for the control groups. Immunofluorescence staining was used to examine the expression of GRP78 in the different tissues. The total RNA and protein were extracted from crushed tissues and used in the reverse transcription polymerase chain reaction and western blot analysis. GRP78 was primarily located in the intracavity of the endoplasmic reticulum. The expression level of GRP78 in the tumor tissue was higher than that in the normal tissue surrounding the tumor $(\mathrm{P}<0.01)$. In addition, the level was higher in the metastatic tumors compared with the non-metastatic tumors $(\mathrm{P}<0.05)$, and in the non-chemotherapy-treated patients compared with the chemotherapy-treated patients $(\mathrm{P}<0.01)$. The expression level of GRP78 mRNA in the tumor tissue was higher than that in the normal tissue $(\mathrm{P}<0.01)$. Furthermore, the level was higher in the metastasis group than in the non-metastasis group $(\mathrm{P}<0.05)$, and in the non-chemotherapy group than in the chemotherapy group $(\mathrm{P}<0.01)$. The expression level of GRP78 protein was higher in the tumor tissue
\end{abstract}

Correspondence to: Dr Yongkui Zhang, Department of Orthopedics, Affiliated Hospital of Shandong University of Traditional Chinese Medicine, 16,369 Jingshi Road, Jinan, Shandong 250014, P.R. China

E-mail: xiaoniu0928@163.com

Key words: osteosarcoma, glucose-regulated protein 78, reverse transcription polymerase chain reaction, western blot analysis compared with the normal tissue $(\mathrm{P}<0.01)$, in the metastasis group compared with the non-metastasis group $(\mathrm{P}<0.05)$, and in the non-chemotherapy group compared with the chemotherapy group $(\mathrm{P}<0.01)$. In conclusion, the present study detected the expression of GRP78 in patients with osteosarcoma and revealed a higher expression level in the tumor tissues compared with the normal tissues around the tumor, in the metastasis group compared with the non-metastasis group and in the non-chemotherapy-treated group compared with the chemotherapy-treated group.

\section{Introduction}

Osteosarcoma is a primary malignant tumor of the skeleton, which frequently occurs in adolescents (1). Due to the infiltrating growth of osteosarcomas, therapeutic approaches have failed to establish a radical cure. However, treatments have improved in the last 30 years with the development of aggressive and efficient combination chemotherapy regimens (1). Although the use of neoadjuvant chemotherapies is effective in prolonging patient survival, they are often associated with the acquisition of drug resistance and the occurrence of adverse reactions, including myelosuppression, hepatotoxicity, toxicity of the kidneys, heart and nervous system, and gastrointestinal reactions $(2,3)$. Therefore, a requirement exists for a novel biomarker that could be used to determine the characteristics and prognosis of osteosarcoma, and that could be applied as a therapeutic target for the gene therapy of osteosarcoma .

Glucose-regulated protein 78 (GRP78), also known as immunoglobulin heavy chain binding protein, is primarily located in the endoplasmic reticulum (ER). The functions of the protein include the facilitation of protein folding, assembly and transport, calcium homeostasis, and the regulation of ER stress signaling (4-6). It has been suggested that the overexpression of GRP78 during periods of cellular stress may be an important defense mechanism, which has a protective effect on cells to ensure cell survival in a variety of adverse conditions. Several previous studies indicated that GRP78 was induced at high levels in malignant tumors, and had an important role in the anti-apoptotic processes of tumor cells. By contrast, GRP78 remained at basal levels in normal tissues $(5,7)$. Gazit et al (8) demonstrated that the level of GRP78 protein was 1.5-3 times higher in human breast cancer cell lines compared with normal epithelial cells. Fernandez et al (9) also confirmed that GRP78 
expression in breast cancer specimens was significantly higher than that in adjacent tissues.

In addition, an overexpression of GRP78 has been detected in several cancers, including brain, breast, lung, prostate, colorectal and gastric cancer, and in hepatocellular carcinoma (HCC) and ureter tumors (10-17). These studies also revealed that GRP78 had an important role in the process of metastasis, and that the knockdown of GRP78 inhibited the invasiveness of cancer cells in vitro, and inhibited the growth and metastasis of a malignant tumor allograft model $(18,19)$. Li et al $(20)$ demonstrated that the knockdown of GRP78 downregulated the expression and activity of matrix metalloproteinase- 2 and TIMP metallopeptidase inhibitor- 2 in HCC cells. In another study, anti-GRP78 autoantibodies were suggested to be potential diagnostic markers for HCC (11). In view of its importance for the survival of cancer cells, GRP78 could be used as an anticancer drug target. Certain anticancer compounds, such as plant-derived genistein, (-)-Epigallocatechin gallate, honokiol and salicylic acid could be used to inhibit the expression or activity of GRP78 (21-23).

GRP78 overexpression is usually associated with high-grade malignant tumors, recurrence and bad prognoses, which have been reported in several malignant tumors. However, the present study did not review the experimental literature concerning patients with osteosarcoma. In addition, numerous studies have demonstrated that GRP78 represents a concordant mechanism of drug resistance in malignant tumors, and could therefore be applied as a predictor for guiding the treatment for patients $(11,20-23)$. The present study aimed to investigate the expression of GRP78 in patients with osteosarcoma, and to analyze the expressional differences in tumor tissue and normal tissue, chemotherapy- and non-chemotherapy-treated patients, and metastatic and non-metastatic tumors. According to these results, the association between the expression of GRP78 and tumor growth, metastasis and chemotherapeutics could be determined. Furthermore, it was hoped that the results of the present study could identify a novel biomarker that could be used to determine the characteristics and prognosis of osteosarcoma, and that could be applied as a therapeutic target for osteosarcoma gene therapies.

\section{Materials and methods}

Specimen selection. Between 2007 and 2012, 60 patients were diagnosed with osteosarcoma at the Affiliated Hospital of Shandong University of Traditional Chinese Medicine (Jinan, China) were selected for the present study. Of these patients, 20 presented with non-metastatic tumors and 40 with metastatic tumors, and 20 had been treated without chemotherapy and 40 with chemotherapy. In addition, 60 specimens from adjacent normal tissues were collected to form the control group. In total, 38 of the cases were male, and 22 were female. The mean age was 16.6 years (range, 6-53 years). All patients had been previously diagnosed with osteosarcoma, exclusive of any other malignant tumor on the locomotor system, using the results from medical imaging, which consisted of radiography, CT and MRI, followed by an open biopsy. All patients had complete follow-up data.

The osteotomy plane was confirmed for all patients at $30 \mathrm{~mm}$ distal from the primary tumor using T1-weighted
MRI (24). Primary tumor specimens were obtained for the experimental group to detect every indicatrix. Normal tissue around the primary tumors was also collected for the control group. In addition, the experimental group was divided into a pre-and post-chemotherapy group, and a metastasis and non-metastasis group. The protocol of the present study was prepared according to the Declaration of Helsinki, and was approved by the Ethics Committee of the Affiliated Hospital of Shandong University of Traditional Chinese Medicine (Jinan, Shandong, China). Written informed consent was obtained from all patients.

Reagents. The rabbit anti-human monoclonal GRP78 antibody was purchased from Cell Signaling Technology, Inc. (Danvers, MA, USA). The fluorescein isothiocyanate (FITC)-labeled goat anti-rabbit immunoglobulin G [IgG; heavy and light $(\mathrm{H}+\mathrm{L})$ chain] was obtained from EarthOx Life Sciences. (Millbrae, CA, USA). The total RNA extraction kit was purchased from Invitrogen Life Technologies (Carlsbad, CA, USA). The reverse transcription polymerase chain reaction (RT-PCR) kit was obtained from Thermo Fisher Scientific (Pittsburgh, PA, USA) and the Bradford protein assay kit was purchased from Bio-Rad Laboratories, Inc. (Hercules, CA, USA). The sequences of the GRP78 gene primer were as follows: Upstream primer, 5'-CGTCCTATGTCGCTT CACT-3'; and downstream primer, 5'-TGTCTT TGTTTGCCCACCTC-3'.

Immunofluorescence staining. The tissue samples, measuring $\sim 1.5 \times 1.5 \times 0.2 \mathrm{~cm}$, were embedded in paraffin following fixation in $4 \%$ paraformaldehyde for $72 \mathrm{~h}$, according to standard laboratory procedures. The paraffin blocks which had been stained with hematoxylin and eosin in order to establish a diagnosis, were used in the subsequent immunofluoresence analysis. First, the paraffin blocks were cut into $7-\mu \mathrm{m}$ sections and open-air dried at room temperature. Next, the tissue sections were fixed in acetone at $4^{\circ} \mathrm{C}$ for $15 \mathrm{~min}$, and washed with phosphate-buffered saline (PBS). The sections were then incubated in 3\% hydrogen peroxide for 5-10 min in order to quench the endogenous peroxidase activity, and then washed again with PBS. Next, the sections were blocked with $50 \mu 15 \%$ normal goat serum (diluted with PBS) and incubated for 20-30 min in a moist chamber. The sections were first incubated with the primary anti-GRP78 antibody (dilution, 1:50) in a moist chamber at $4^{\circ} \mathrm{C}$ for $36 \mathrm{~h}$, prior to washing three times with PBS. Next, the sections were incubated with a goat anti-rabbit IgG/FITC antibody (dilution, 1:200) in a moist chamber at $37^{\circ} \mathrm{C}$ for $30 \mathrm{~min}$, prior to washing three times with PBS. The sections were then blocked with glycerol following incubation with DAPI (dilution, 1:200) for $5 \mathrm{~min}$ at room temperature.

Sections of normal tissue were similarly prepared, using each assay as a positive control. Subsequent to performing all steps, except for the addition of the primary antibody, each case had a negative control specimen.

The sections were analyzed using a Leica DM4000B microscope (Leica Microsystems GmbH, Wetzlar, Germany), and images were captured using the Image Pro Plus image analysis system 7.0 (Media Cybernetics, Inc., Rockville, MD, USA) in order to detect the expression level. Histiocytes in 
Table I. Immunofluorescence staining results of GRP78 in normal and tumor tissues $(n=60)$.

Tumor tissue

\begin{tabular}{|c|c|c|c|c|c|}
\hline \multirow[b]{3}{*}{ Variable } & \multirow[b]{3}{*}{ Normal tissue } & \multirow{2}{*}{\multicolumn{2}{|c|}{ Chemotherapy }} & & \\
\hline & & & & \multicolumn{2}{|c|}{ Non-chemotherapy } \\
\hline & & Non-metastasis & Metastasis & Non-metastasis & Metastasis \\
\hline $\mathrm{n}$ & 60 & 10 & 30 & 10 & 10 \\
\hline Fluorescence intensity & $0.57 \pm 0.13$ & $1.51 \pm 0.22^{\mathrm{a}}$ & $1.89 \pm 0.35^{\mathrm{a}, \mathrm{b}}$ & $2.15 \pm 0.44^{\mathrm{a}, \mathrm{c}}$ & $2.91 \pm 0.57^{\mathrm{a}, \mathrm{b}, \mathrm{c}}$ \\
\hline
\end{tabular}

which the cytoplasm was stained green were considered to be GRP78-positive cells.

$R T$-PCR. The total RNA was extracted using a total RNA extraction kit, according to the manufacturer's instructions. Overall, $3 \mu \mathrm{g}$ total RNA was subjected to RT-PCR using M-MuLV reverse transcriptase (Thermo Fisher Scientific) and oligo $(\mathrm{dT})_{18}$ primers. PCR was performed in the presence of $25 \mathrm{mM} \mathrm{Mg}^{2+}$, using equal amounts of cDNA, 1 unit of Taq polymerase (Promega Corporation, Madison, WI, USA) and $20 \mathrm{mM}$ of the following primers: Forward, 5'-CGTCCT ATGTCGCCTTCACT-3'; and reverse, 5'-TGTCTTTGTTTG CCCACCTC-3'. The cycling parameters (30 cycles) were as follows: Denaturation at $94^{\circ} \mathrm{C}$ for $1 \mathrm{~min}$, annealing at $58^{\circ} \mathrm{C}$ for $1 \mathrm{~min}$ and extension at $72^{\circ} \mathrm{C}$ for $1 \mathrm{~min}$. All experiments were performed in triplicate. Next, $3 \mu \mathrm{l} \mathrm{PCR}$ product with $0.5 \mu 15 \mathrm{X}$ loading buffer was transferred to a $2 \%$ agarose gel electrophoresis system with conditions of $120 \mathrm{~V}$ and $100 \mathrm{~mA}$ for $30 \mathrm{~min}$. The electropherogram was transferred to the electrophoresis image analysis system to measure the expression intensity of GRP78 mRNA. The formula of the relative level of GRP78 mRNA expression was as follows: Relative level of GRP78 mRNA $=$ value of GRP78 mRNA in samples / value of $\beta$-actin in samples.

Western blot analysis. In total, $100 \mathrm{mg}$ of frozen tissue samples were homogenized in $400 \mu \mathrm{l}$ ice-cold RIPA buffer [containing phenylmethylsulfonyl fluoride]. Following $30 \mathrm{~min}$ of schizolysis on ice, the samples were spun at $12,000 \mathrm{x} g$ for $5 \mathrm{~min}$ at $4^{\circ} \mathrm{C}$ and the supernatants were collected. Next, two additional centrifugations at 2,500 x g were performed in order to produce clarified lysates. The protein concentrations of the resulting lysates were determined using the Bradford Protein Assay kit. Sample volumes equivalent to $30 \mu \mathrm{g}$ of protein were aliquotted, normalized to equivalent volumes of RIPA buffer, and then lyophilized in vacuo at a low heat. The samples were then rehydrated with $10 \mathrm{ml}$ of deionized water followed by an equivalent volume of electrophoresis sample buffer $(1.0 \mathrm{ml}$ glycerol, $0.5 \mathrm{ml} \beta$-mercaptoethanol, $3.0 \mathrm{ml} \mathrm{10 \%}$ SDS, $1.25 \mathrm{ml} 1.0 \mathrm{M}$ Tris- $\mathrm{HCl} \mathrm{pH} 6.7$ and 1-2 mg bromophenol blue). Next, the samples were denatured at $90^{\circ} \mathrm{C}$ for $5 \mathrm{~min}$, loaded onto an $8 \%$ SDS-polyacrylamide gel containing a $4 \%$ stacking gel and electrophoresed at $100 \mathrm{~V}$ for $1.5 \mathrm{~h}$ in Tris-glycine running buffer $(25 \mathrm{mM}$ Tris-base,
$250 \mathrm{mM}$ glycine and $0.1 \% \mathrm{SDS}$ ). In addition to the pairs of tumor and normal tissue samples, each gel was also loaded with a molecular weight standard. The proteins were electroblotted onto a nitrocellulose membrane (Gelman Sciences, Ann Arbor, MI, USA) at $60 \mathrm{~V}$ for $3 \mathrm{~h}$. Next, the membrane was blocked for $1 \mathrm{~h}$ with $1 \%$ bovine serum albumin (BSA) in Tris-buffered saline with Tween-20 [TBST; $10 \mathrm{mM}$ Tris- $\mathrm{HCl}$ (pH 8.0), $150 \mathrm{mM} \mathrm{NaCl}$ and $0.05 \%$ Tween-20] with gentle shaking at room temperature, and then incubated overnight at $4{ }^{\circ} \mathrm{C}$ without agitation in $1 \% \mathrm{BSA} / \mathrm{TBST}$ containing a GRP78 monoclonal antibody (dilution, 1:1,000), and an actin monoclonal antibody (dilution, 1:500). Following two rinses with TBST, the membrane was washed in TBST with gentle shaking for $1 \mathrm{~h}$, with buffer changes every $10 \mathrm{~min}$. The membrane was then incubated in $1 \%$ BSA/TBST containing an FITC goat anti-rabbit IgG secondary antibody (1:5,000 dilution) for $1 \mathrm{~h}$ with gentle shaking. Following two rinses with TBST, the membrane was washed in TBST with gentle shaking for $1 \mathrm{~h}$, with buffer changes every $5 \mathrm{~min}$.

GRP78 and $\beta$-actin protein expression was simultaneously detected using an enhanced chemiluminescence detection system (DuPont NEN, Boston, CA, USA). The signals were visualized by autoradiography and quantified with densitometry. GRP78 protein expression was normalized to $\beta$-actin for the loading control. The expression level of GRP78 protein was indicated by the optical density value.

Statistical analysis. Data are expressed as the mean \pm standard deviation. Statistical analysis was performed using a one-way analysis of variance and Tamhane's T2 test to determine significant differences among the groups. $\mathrm{P}<0.05$ was used to indicate a statistically significant difference.

\section{Results}

Immunofluorescence staining. GRP78 was mainly located in the ER. Histiocytes in which the cytoplasm was stained green were considered to be GRP78-positive cells. The expression level of GRP78 in the tumor tissue was significantly higher than that in the normal tissue surrounding the tumor $(\mathrm{P}<0.01)$. Furthermore, the expression level of GRP78 was correlated to metastasis and chemotherapy status (Figs. 1-5). As shown in Table I, there was a significant difference between the non-chemotherapy and chemotherapy groups $(\mathrm{P}<0.01)$. 


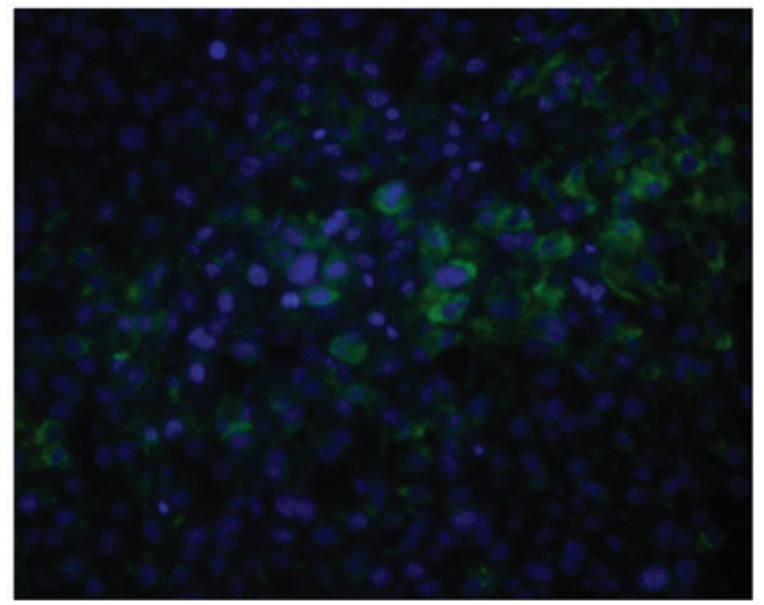

Figure 1. Expression of glucose-regulated protein 78 in normal tissue (magnification, $\mathrm{x} 400$ ).

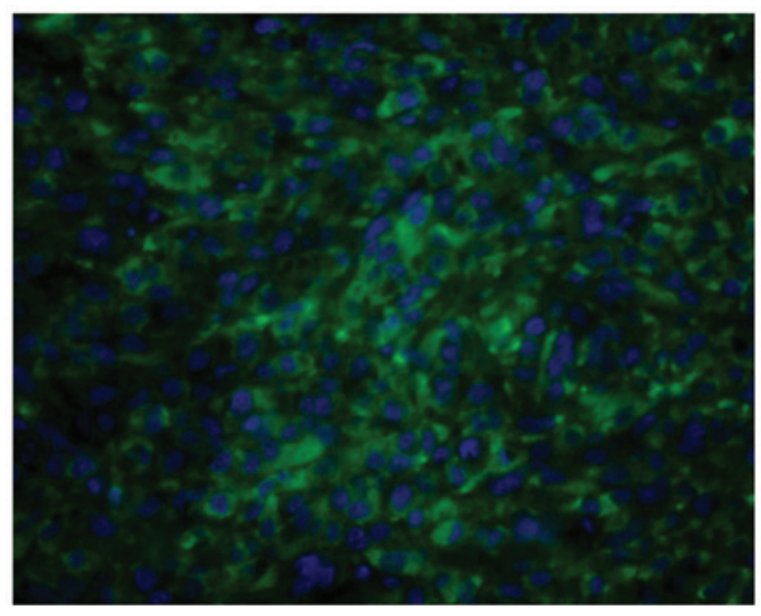

Figure 2. Expression of glucose-regulated protein 78 in metastatic tumor tissue not treated with chemotherapy (magnification, $\mathrm{x} 400$ ).

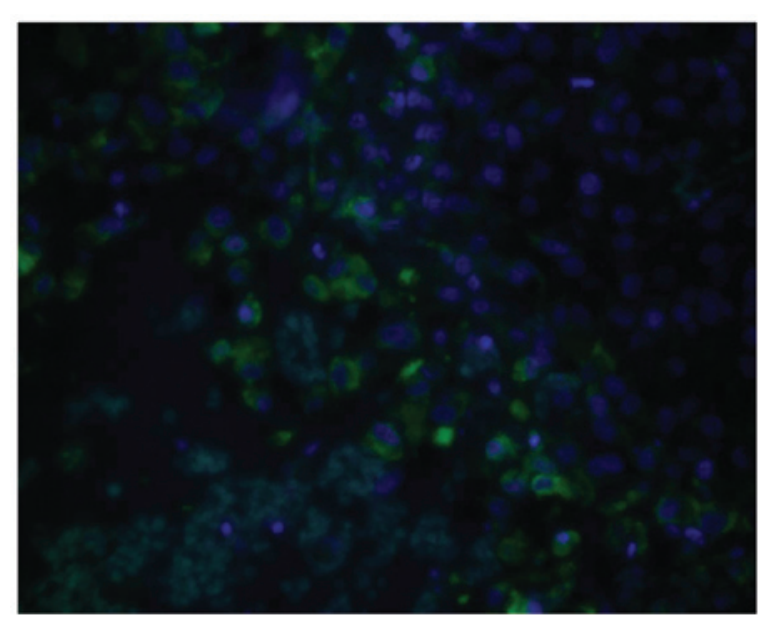

Figure 3. Expression of glucose-regulated protein 78 in non-metastatic tumor tissue that was treated with chemotherapy (magnification, $\mathrm{x} 400$ ).

In addition, the expression level of GRP78 in the metastasis group was higher than that in the non-metastasis group $(\mathrm{P}<0.05)$.

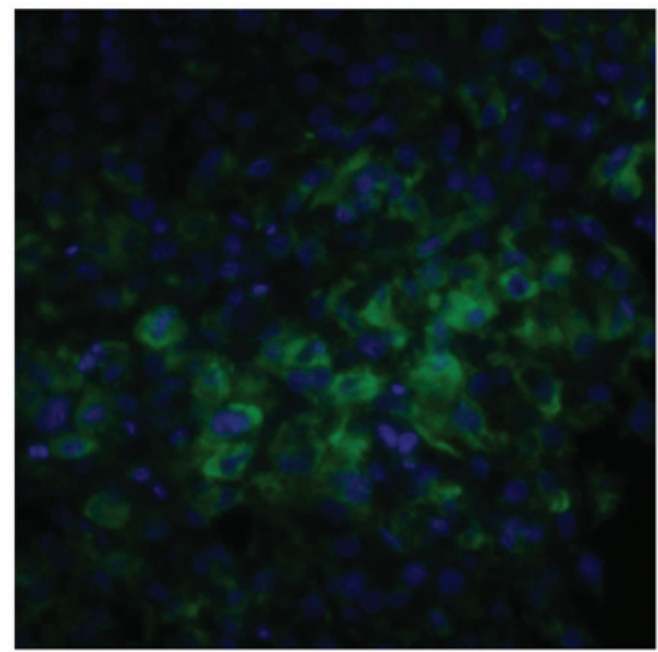

Figure 4. Expression of glucose-regulated protein 78 in metastatic tumor tissue that was metastatic (magnification, $\mathrm{x} 400$ ).

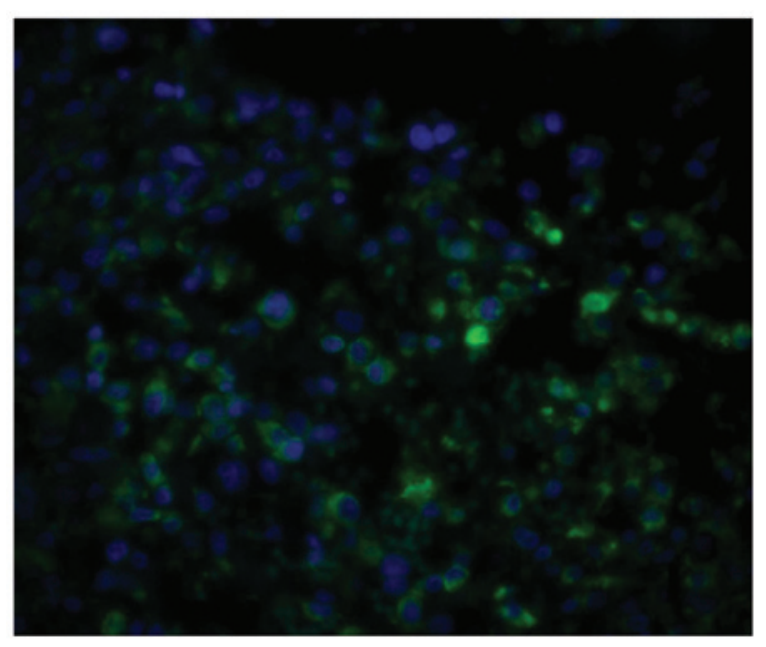

Figure 5. Expression of glucose-regulated protein 78 in non-metastatic tumor tissue that was not metastatic (magnification, $\mathrm{x} 400$ ).

RT-PCR. GRP78 mRNA was identified in all specimens. As shown in Table II, the expression level of GRP78 mRNA was $0.24 \pm 0.02$ in normal tissue, which was significantly lower than that in the tumor tissue $(\mathrm{P}<0.01)$. Furthermore, the expression level of GRP78 mRNA in the tumor tissues was correlated to metastasis and chemotherapy status (Fig. 6). The expression level of GRP78 mRNA in the metastasis group was higher than in the non-metastasis group $(\mathrm{P}<0.05)$. The expression level was also higher in the non-chemotherapy group than in the chemotherapy group $(\mathrm{P}<0.05)$.

Western blot analysis. GRP78 protein was expressed in all specimens. The expression level of GRP78 protein in the tumor tissue was significantly higher than in the normal tissue surrounding the tumor $(\mathrm{P}<0.01)$, which was consistent with the results of the immunofluorescence staining (Fig. 7). Furthermore, the expression level of GRP78 protein in the tumor tissues was correlated with metastasis and chemotherapy status. The expression level of GRP78 protein in the metastasis group was higher than in the non-metastasis 
Table II. Immunofluorescence staining results of GRP78 in normal tissue and tumor tissue (n=60).

\begin{tabular}{|c|c|c|c|c|c|}
\hline \multirow[b]{3}{*}{ Variable } & \multirow[b]{3}{*}{ Normal tissue } & \multicolumn{4}{|c|}{ Tumor tissue } \\
\hline & & \multicolumn{2}{|c|}{ Chemotherapy } & \multicolumn{2}{|c|}{ Non-chemotherapy } \\
\hline & & Non-metastasis & Metastasis & Non-metastasis & Metastasis \\
\hline $\mathrm{n}$ & 60 & 10 & 30 & 10 & 10 \\
\hline Relative expression & $0.24 \pm 0.02$ & $0.70 \pm 0.05^{\mathrm{a}}$ & $1.21 \pm 0.04^{\mathrm{a}, \mathrm{b}}$ & $1.54 \pm 0.06^{\mathrm{a}, \mathrm{c}}$ & $1.87 \pm 0.05^{\mathrm{a}, \mathrm{b}, \mathrm{c}}$ \\
\hline
\end{tabular}

Table III. Expression level of GRP78 protein in normal tissue and tumor tissue $(n=60)$.

\begin{tabular}{|c|c|c|c|c|c|}
\hline \multirow[b]{3}{*}{ Variable } & \multirow[b]{3}{*}{ Normal tissue } & \multicolumn{4}{|c|}{ Tumor tissue } \\
\hline & & \multicolumn{2}{|c|}{ Chemotherapy } & \multicolumn{2}{|c|}{ Non-chemotherapy } \\
\hline & & Non-metastasis & Metastasis & Non-metastasis & Metastasis \\
\hline $\mathrm{n}$ & 60 & 10 & 30 & 10 & 10 \\
\hline OD value & $210.53 \pm 4.74$ & $271.63 \pm 4.97^{\mathrm{a}}$ & $315.29 \pm 6.46^{\mathrm{a}, \mathrm{b}}$ & $366.78 \pm 5.82^{\mathrm{a}, \mathrm{c}}$ & $454.31 \pm 7.35^{\mathrm{a}, \mathrm{b}, \mathrm{c}}$ \\
\hline
\end{tabular}

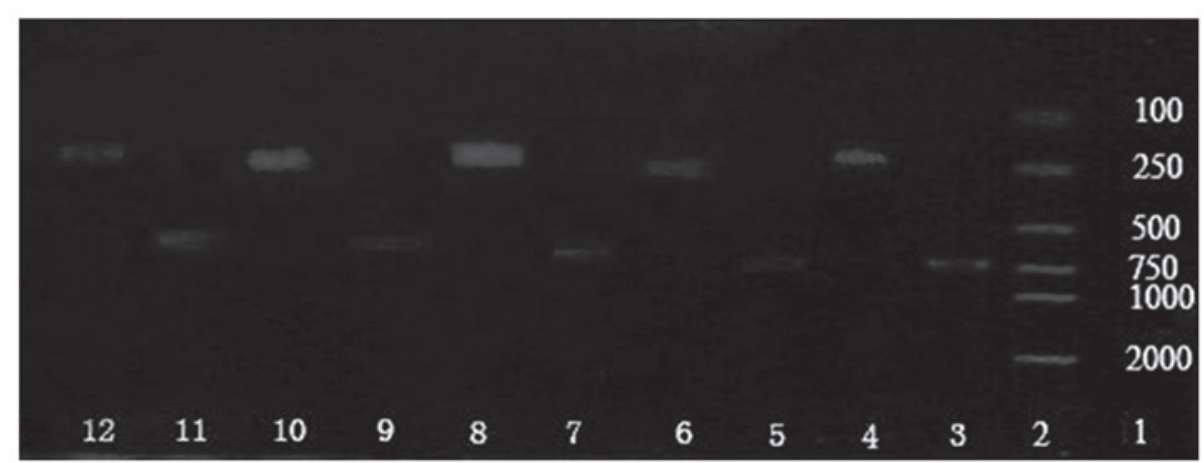

Figure 6. Expression of GRP78 mRNA in normal and tumor tissues. Lane 1, marker DL20006; lane 2, prestained protein molecular weight marker; lane 3 , $\beta$-actin in metastatic tumor tissue treated with chemotherapy; lane 4, GRP78 in metastatic tumor tissue treated with chemotherapy; lane 5, $\beta$-actin in non-metastatic tumor tissue treated with chemotherapy; lane 6, GRP78 in non-metastatic tumor tissue treated with chemotherapy; lane 7, $\beta$-actin in metastatic tumor tissue treated without chemotherapy; lane 8 , GRP78 in metastatic tumor tissue treated without chemotherapy; lane 9 , $\beta$-actin in non-metastatic tumor tissue treated without chemotherapy; lane 10, GRP78 in non-metastatic tumor tissue treated without chemotherapy; lane 11, $\beta$-actin in normal tissue; lane 12 , GRP78 in normal tissue. GRP78, glucose-regulated protein 78.

group $(\mathrm{P}<0.05)$. The expression level was also higher in the non-chemotherapy group than in the chemotherapy group $(\mathrm{P}<0.01$; Table III).

\section{Discussion}

GRP78 belongs to the Hsp70 family of proteins and was identified as a glucose-deficiency protein alongside GRP94 and GRP58 in the late 1970s. The protein is recognized as a major molecular chaperone and signal-regulated factor in the ER stress signaling pathway $(4,5)$. The results of previous studies have suggested that the overexpression of GRP78 in periods of cellular stress may be an important defense mechanism, which has a protective effect on cells and ensures cell survival in the presence of a variety of adverse factors (6). GRP78 is primarily located at the ER, which is consistent with the results of the immunofluorescence staining analysis in the present study. In the present study, histiocytes in 


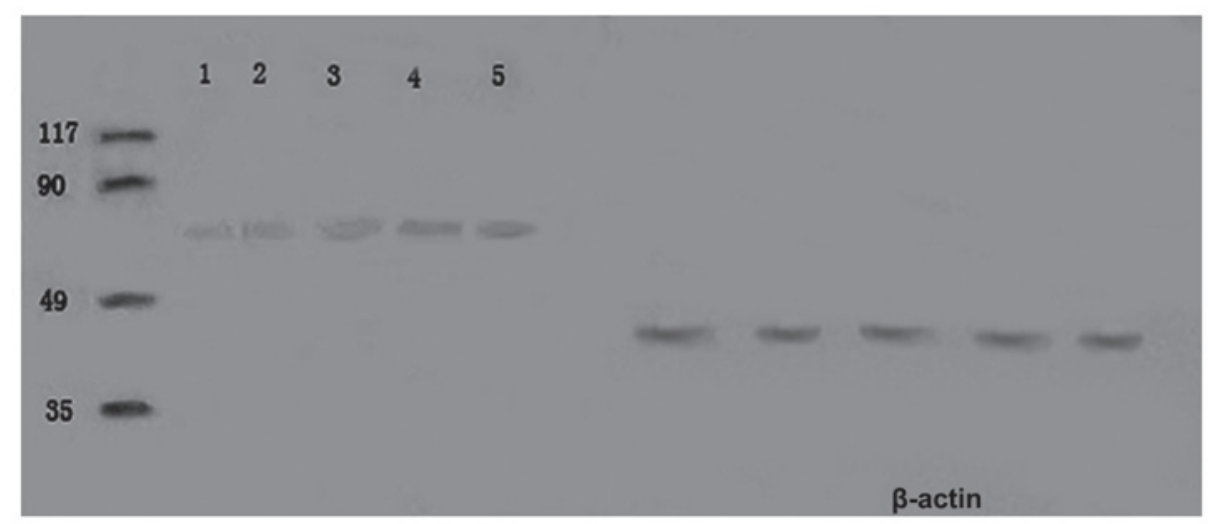

Figure 7. Expression of GRP78 protein in normal and tumor tissues. Lane 1, GRP78 protein in normal tissue; lane 2, GRP78 protein in metastatic tumor tissue treated with chemotherapy; lane 3, GRP78 protein in non-metastatic tumor tissue treated with chemotherapy; lane 4, GRP78 protein in metastatic tumor tissue treated without chemotherapy; lane 5, GRP78 protein in non-metastatic tumor tissue treated without chemotherapy. GRP78, glucose-regulated protein 78.

which the cytoplasm was stained green were considered to be GRP78-positive cells.

A previous study revealed that GRP78 decreased the cytotoxic $\mathrm{T}$ cell-mediated destruction of tumor cells, promoted tumor formation and resistance to chemotherapy, and prevented apoptosis (25). Furthermore, several studies have indicated that GRP78 is induced at high levels in malignant tumors, despite GRP78 remaining at low levels in the main organs. Gazit et al (8) demonstrated that the protein level of GRP78 was 1.5-3 times higher in a human breast cancer cell line compared with normal epithelial cells. In addition, Fernandez et al (9) confirmed that GRP78 expression in breast cancer specimens was significantly higher than in adjacent tissues. A study by Koomägi et al (18) indicated that GRP78 was overexpressed in human non-small cell lung cancer. Furthermore, a number of previous studies demonstrated that GRP78 was induced and expressed at a high level in brain, prostate, colorectal and gastric cancers, and in HCCs and ureter tumors $(10-12,14,15,17)$. Using immunohistological staining, RT-PCR and western blotting, the present study revealed that the expression level of GRP78 in human osteosarcoma tissues was higher than that in the normal tissues surrounding the tumors. To the best of our knowledge, this is the first study to demonstrate the overexpression of GRP78 in human osteosarcoma.

In recent years, studies have attempted to investigate the association between GRP78 expression and tumor stage and patient survival. In a retrospective cohort study, it was revealed that high GRP78 expression in visceral adipocytes from endometrial cancer patients was positively correlated with advanced-stage disease, deep myometrial invasion and decreased disease-free survival time (26). Park et al (17) also demonstrated that the overexpression of GRP78 in patients with ureter tumors was associated with a high tumor (T) stage and nuclear grade, a high bladder cancer recurrence rate and a low survival rate.

Another previous study, which analyzed 137 renal cell carcinoma specimens, established that there was a significant association between GR P78 positivity and a higher tumor grade, an advanced $\mathrm{T}$ stage, lymphovascular invasion, regional nodal involvement and distant metastases (27). In the present study, despite the association between GRP78 and osteosarcoma grade, a correlation with the $\mathrm{T}$ stage was not detected. However, it was identified that the expression level of GRP78 in the metastasis group was higher than that in the non-metastasis group. However, certain studies contradict the findings of the present study. For example, Hardy et al (28) demonstrated that GRP78 negativity was correlated with a high colon cancer cell proliferation rate and the presence of liver metastasis in nude mice. By contrast, GRP78-positive cells exhibited reduced proliferation, tumor growth and liver metastasis. Therefore, whether or not the expression level of GRP78 and its role in tumor cells is associated with the origin of the tumor cells requires further investigation.

Due to its protective effect upon tumor cells, GRP78 could be used as a target of chemotherapy. The suppression of GRP78 could increase the apoptosis of tumor cells, slow down tumor growth and improve patient survival. Furthermore, recent studies verified that targeting GRP78 promoted apoptosis and overcame resistance to drug-induced cell death in several cancer cells (29-31). Kuo et al (32) demonstrated that silencing GRP78 not only inhibited the formation of colon cancer tumors, but also decreased the expression of vascular endothelial growth factor (VEGF) and VEGF receptor 2. Furthermore, certain studies have used overexpressed GRP78 as a target protein for guiding drugs to gastric cancer tumor cells, which may lead to the precise targeting of tumor cells and less side-effects (33). The present study established that the expression level of GRP78 in the non-chemotherapy group was higher than that in the chemotherapy group. This result demonstrated that chemotherapeutics are able to decrease the expression level of GRP78 in human osteosarcoma cells. However, whether or not GRP78 is the primary molecular target involved in this process should be investigated further.

Using immunohistological staining, RT-PCR and western blot analysis, the present study revealed that the expression level of GRP78 in human osteosarcoma tissues was higher than that in the normal tissues surrounding the tumor. The expression level was also higher in the metastasis group compared with the non-metastasis group, and in the non-chemotherapy group compared with the chemotherapy group. The results indicated that there was a direct association between GRP78 expression and tumor growth, metastasis and chemotherapy. The results of the present study not only verified the expression of GRP78 in 
human osteosarcoma cells, but also provided experimental and theoretical evidence for the evaluation of therapy and prognosis. Therefore, it can be concluded that GRP78 should be applied as a molecular target in order to analyze tumor behaviors and therapeutic reactions. In a clinical setting, GRP78 may represent a novel biomarker that could be used to determine the development and prognosis of osteosarcomas. Combination therapies for suppressing GRP78 expression could inhibit tumor growth, increase sensitivity to chemotherapy, suppress metastasis and improve the prognosis. Such treatments could therefore be applied as a novel form of gene therapy for osteosarcoma. However, further studies are required in order to determine whether the combined application of GRP78 inhibitors and conventional chemotherapies could enhance the efficacy of drugs and cure primary tumors, and whether GRP78 could be applied as a serological diagnostic biomarker for osteosarcoma.

\section{Acknowledgements}

This study was supported by the National Science Foundation of Shandong Province (grant. no. ZR2014HQ034).

\section{References}

1. Picci P: Osteosarcoma (osteogenic sarcoma). Orphanet J Rare Dis 2: 6, 2007.

2. Uchida A: Recent advances in management of musculoskeletal tumors. Gan To Kagaku Ryoho 26: 185-190, 1999 (In Japanese).

3. Bacci G and Lari S: Current treatment of high grade osteosarcoma of the extremity: review. J Chemother 13: 235-243, 2001.

4. Lee AS: The glucose-regulated proteins: stress induction and clinical applications. Trends Biochem Sci 26: 504-510, 2001.

5. Hendershot LM: The ER function $\mathrm{BiP}$ is a master regulator of ER function. Mt Sinai J Med 71: 289-297, 2004.

6. Lee AS: GRP78 induction in cancer: therapeutic and prognostic implications. Cancer Res 67: 3496-3499, 2007.

7. Pfaffenbach KT and Lee AS: The critical role of GRP78 in physiologic and pathologic stress. Curr Opin Cell Biol 23: 150-156, 2011.

8. Gazit G, Lu J and Lee AS: De-regulation of GRP stress protein expression in human breast cancer cell lines. Breast Cancer Res Treat 54: 135-146, 1999

9. Fernandez PM, Tabbara SO, Jacobs LK, Manning FC, Tsangaris TN, Schwartz AM, Kennedy KA and Patierno SR: Overexpression of the glucose regulated stress gene GRP78 in malignant but not benign human breast lesions. Breast Cancer Res Treat 59: 15-26, 2000.

10. Tsunemi S, Nakanishi T, Fujita Y, Bouras G, Miyamoto Y, Miyamoto A, Nomura E, Takubo $\mathrm{T}$ and Tanigawa $\mathrm{N}$ : Proteomics-based identification of a tumor-associated antigen and its corresponding autoantibody in gastric cancer. Oncol Rep 23: 949-956, 2010.

11. Shao Q, Ren P, Li Y, Peng B, Dai L, Lei N, Yao W, Zhao G, Li L and Zhang J: Autoantibodies against glucose-regulated protein 78 as serological diagnostic biomarkers in hepatocellular carcinoma. Int J Oncol 41: 1061-1067, 2012.

12. Zhang LH, Yang XL, Zhang X, Cheng JX and Zhang W: Association of elevated GRP78 expression with increased astrocytoma malignancy via Akt and ERK pathways. Brain Res 1371: 23-31, 2011.

13. Uramoto H, Sugio K, Oyama T, Nakata S, Ono K, Yoshimatsu T, Morita $\mathrm{M}$ and Yasumoto $\mathrm{K}$ : Expression of endoplasmic reticulum molecular chaperone Grp78 in human lung cancer and its clinical significance. Lung Cancer 49: 55-62, 2005.

14. Xing X, Li Y, Liu H, Wang L and Sun L: Glucose regulated protein 78 (GRP78) is overexpressed in colorectal carcinoma and regulates colorectal carcinoma cell growth and apoptosis. Acta Histochem 113: 777-782, 2011.

15. Daneshmand S, Quek ML, Lin E, Lee C, Cote RJ, Hawes D, Cai J, Groshen S, Lieskovsky G, Skinner DG, et al: Glucose-regulated protein GRP78 is up-regulated in prostate cancer and correlates with recurrence and survival. Hum. Pathol 38: 1547-1552, 2007.
16. Zhang J, Jiang Y, Jia Z, Li Q, Gong W, Wang L, Wei D, Yao J, Fang S and Xie K: Association of elevated GRP78 expression with increased lymph node metastasis and poor prognosis in patients with gastric cancer. Clin Exp Metastasis 23: 401-410, 2006.

17. Park CH, Choi MS, Ha JY, Kim BH, Park CH and Kim CI: Effect of overexpression of glucose-regulated protein 78 and bcl-2 on recurrence and survival in patients with ureter tumors. Korean J Urol 54: 671-676, 2013.

18. Koomägi R, Mattern J and Volm M: Glucose-related protein (GR P78) and its relationship to drug-resistance proteins PI70, GST-pi, LRP56 and angiogenesis in non-small cell lung carcinomas. Anticancer Res 19: 4333-4336, 1999.

19. Linnik KM and Herscovitz H: Multiple molecular chaperones interact with apoliprotein B during its maturation: The network of endoplasmic reticulum-resident chaperones (ERp72, GRP94, calreticulin, and $\mathrm{BiP}$ ) interacts with apoliprotein $\mathrm{b}$ regardless of its lipidation state. J Biol Chem 273: 21368-21373, 1998.

20. Li H, Song H, Luo J, Liang J, Zhao S and Su R: Knockdown of glucose-regulated protein 78 decreases the invasion, metalloproteinase expression and ECM degradation in hepatocellular carcinoma cells. J Exp Clin Cancer Res 31: 39, 2012.

21. Ermakova SP, Kang BS, Choi BY, Choi HS, Schuster TF, Ma WY, Bode AM and Dong Z: (-)-Epigallocatechin gallate overcomes resistance to etoposide-induced cell death by targeting the molecular chaperone glucose-regulated protein 78. Cancer Res 66: 9260-9269, 2006.

22. Deng WG, Ruan KH, Du M, Saunders MA and Wu KK: Aspirin and salicylate bind to immunoglobulin heavy chain binding protein $(\mathrm{BiP})$ and inhibit its ATPase activity in human fibroblasts. FASEB J 15: 2463-2470, 2001.

23. Martin S, Lamb HK, Brady C, Lefkove B, Bonner MY, Thompson P, Lovat PE, Arbiser JL, Hawkins AR and Redfern CP: Inducing apoptosis of cancer cells using small-molecule plant compounds that bind to GRP78. Br J Cancer 109: 433-443, 2013.

24. Hao YK, Zhang YK, Yang ZP, Li X, Yang Q and Li JM: The accuracy of magnetic resonance imaging in determining osteotomy plane in osteosarcoma. Orthopedics 31: 544, 2008.

25. Dong D, Dubeau L, Bading J, Nguyen K, Luna M, Yu H, Gazit-Bornstein G, Gordon EM, Gomer C, Hall FL, Gambhir SS and Lee AS: Spontaneous and controllable activation of suicide gene expression driven by the stress-inducible grp78 promoter resulting in eradication of sizable human tumors. Hum Gene Ther 15: 553-561, 2004.

26. Matsuo K, Gray MJ, Yang DY, Srivastava SA, Tripathi PB, Sonoda LA, Yoo EJ, Dubeau L, Lee AS and Lin YG: The endoplasmic reticulum stress marker, glucose-regulated protein-78 (GRP78) in visceral adipocytes predicts endometrial cancer progression and patient survival. Gynecol Oncol 128: 552-559, 2013.

27. Kuroda K, Horiguchi A, Asano T, Ito K, Asakuma J, Sato A, Yoshii H, Hayakawa M, Sumitomo M and Asano T: Glucose-regulated protein 78 positivity as a predictor of poor survival in patients with renal cell carcinoma. Urol Int 87: 450-456, 2011.

28. Hardy B, Raiter A, Yakimov M, Vilkin A and Niv Y: Colon cancer cells expressing cell surface GRP78 as a marker for reduced tumorigenicity. Cell Oncol (Dordr) 35: 345-354, 2012.

29. Park HR, Tomida A, Sato S, Tsukumo Y, Yun J, Yamori T, Hayakawa Y, Tsuruo T and Shin-ya K: Effect on tumor cells of blocking survival response to glucose deprivation. J Natl Cancer Inst 96: 1300-1310, 2004.

30. Gupta P, Walter MR, Su ZZ, Lebedeva IV, Emdad L, Randolph A, Valerie K, Sarkar D and Fisher PB: BiP/GRP78 is an intracellular target for MDA-7/IL-24 induction of cancer-specific apoptosis. Cancer Res 66: 8182-8191, 2006.

31. Gonzalez-Gronow M, Cuchacovich M, Llanos C, Urzua C, Gawdi G and Pizzo SV: Prostate cancer cell proliferation in vitro is modulated by antibodies against glucose-regulated protein 78 isolated from patient serum. Cancer Res 66: 11424-11431, 2006.

32. Kuo LJ, Hung CS, Chen WY, Chang YJ and Wei PL: Glucose-regulated protein 78 silencing down-regulates vascular endothelial growth factor/vascular endothelial growth factor receptor 2 pathway to suppress human colon cancer tumor growth. J Surg Res 185: 264-272, 2013.

33. Cheng CC, Lu N, Peng CL, Chang CC, Mai FD, Chen LY, Liao MH, Wang WM and Chang J: Targeting to overexpressed glucose-regulated protein 78 in gastric cancer discovered by 2D DIGE improves the diagnostic and therapeutic efficacy of micelles-mediated system. Proteomics 12: 2584-2597, 2012. 